\title{
THE IMPORTANCE OF THE STUDY OF THE HEMODYNAMICS OF THE UTERINE TUMORS BY THE METHOD OF DOPPLEROMETRY IN THE TWO- AND THREE-DIMENSIONAL ECHOGRAPHY MODES FOR DIFFERENTIAL DIAGNOSTICS OF SIMPLE, PROLIFERATING LEIOMYOMAS AND UTERINE SARCOMAS (REVIEW OF LITERATURE)
}

\author{
Kirill Yakovenko \\ SI «Grigoriev Institute for Medical Radiology of NAMS of Ukraine» \\ 82 Pushkinskaya str., Kharkiv, Ukraine, 61024 \\ kiras2001@ukr.net \\ Vladyslav Sukhin \\ Department of Oncogynecology \\ SI «Grigoriev Institute for Medical Radiology, NAMS of Ukraine» \\ 82 Pushkinska str., Kharkiv, Ukraine, 61024 \\ suhinvvlad@ukr.net \\ Tamara Tamm \\ Department of Surgery and Proctology \\ Kharkiv Medical Academy of Postgraduate Education \\ 58 Amosova str., Kharkiv, Ukraine, 61176 \\ tamm_ti@ukr.net \\ Elena Yakovenko \\ Department of Genetics, Obstetrics, Gynecology and Fetal Medicine \\ Kharkiv Medical Academy of Postgraduate Education \\ 58 Amosova str., Kharkiv, Ukraine, 61176 \\ yakovenkoelen@ukr.net
}

\begin{abstract}
The article analyzes modern literature data on the importance of studying the hemodynamics of uterine tumors with dopplerometry in two- and three-dimensional regimens of echography for differential diagnosis of simple proliferating leiomyomas and sarcomas of the uterus. It is shown that the differential diagnosis of benign and malignant tumors using the dopplerometry is based on various features of the blood supply of these tumors. On the basis of the analysis of literature data, it was concluded that in the dopplerometry evaluation of benign, borderline and malignant tumors of myometrium in the two-dimensional regime, there were differences in the localization of the detected vessels in the CDM regimen, in the rates of vascular blood flow and vascular resistance in pulse dopplerometry. For a simple leiomyoma, the absence of a central intra-node localization of blood vessels in the CDM regimen, a low rate of arterial and venous blood flow, as well as an average resistance of arterial blood flow in the regime of impulsive dopplerometry are most typical; in a leiomyoma with eating disorders, the absence of a central intra-node localization of blood vessels, a low rate of arterial and venous blood flow in combination with high arterial resistance were more often observed. For the proliferating leiomyoma, the central intra-node localization of the vessels and the average blood flow velocities with low and medium resistance are characteristic. For sarcoma of the uterus, there is abundant vascularization both around the periphery and in the center, high blood flow rates and low resistance. The authors emphasize that there is information about the low specificity of this gradation, since the detection of a central type of vascularization and low resistance values can be in simple myomatous nodes with edema, eating disorders and destruction, and leads to diagnostic errors and suspicion of malignancy. In the three-dimensional dopplerometry mode for simple leiomyomas, low indices of volume perfusion indices were characteristic, and for proliferating leiomyomas and sarcomas of the uterus - high indices of volume perfusion indices exceeding those in the uterus as a whole.

Based on the review of the literature, the authors concluded that the presently available echographic and dopplerometric two- and three-dimensional markers are characterized by high sensitivity, but very low specificity. The low specificity of the known
\end{abstract}


ultrasonic and dopplerometric criteria combined with the rarity of cases of sarcoma in the uterus against the background of a large number of similar echographically and dopplerometrically leiomyomas lead to low diagnostic accuracy of ultrasound diagnostics. This situation requires a further continuation of the scientific search for differential diagnostic ultrasound criteria by leiomyomas and sarcomas of the uterus using modern technologies, including three-dimensional echography.

Keywords: ultrasound diagnostics, three-dimensional echography, dopplerometry, simple leiomyoma, proliferating leiomyoma, uterine sarcoma.

\section{Introduction}

Differential ultrasound diagnosis of benign, borderline and malignant tumors remains a problem that has not been fully solved to date, despite the fact that ultrasound has become a routine method over the past decade, its significance in the diagnosis of various oncological diseases has been proven and sufficiently covered in the literature $[1,2]$. According to the comparison of the ultrasound and morphological pattern of macro preparations with the histology of distant tumors, experience is gradually accumulating, allowing the sonologist to assume the presence of oncopathology in the patient at the preclinical stage, analyzing only the echography data [3, 4]. However, despite this, the frequency of detection of early forms of malignant tumors using the ultrasound diagnosis method has been insufficient in clinical practice for many years [5].

At the present stage of the development of medicine, the diagnostic capabilities of echography have expanded significantly with the advent of methods such as color Doppler mapping (CDM), energy Doppler mapping (EDR), wavelet Doppler ultrasound (WDU), 3D energy Doppler ultrasonography $[6,7]$.

\section{Aim of the research}

To analyze the current literature data on the diagnostic significance of the study of hemodynamics of uterine tumors by the method of dopplerometry in two- and three-dimensional regimens of echography to determine the direction of further scientific search for new markers of differential diagnosis of simple, proliferating leiomyomas and sarcoma of the uterus using three-dimensional echography.

3. The importance of the study of the hemodynamics of the uterine tumors by the method of dopplerometry in the two- and three-dimensional echography modes for differential diagnostics of simple, proliferating leiomyomas and uterine sarcoma (review of literature).

The first reports on the use of the Doppler method for the differential diagnosis of benign and malignant formations of the female genital area were published in 1989 by three independent groups of researchers [8, 9]. It was then first proposed to use the parameters of the maximum arterial velocity (MAV) of the intra-tumoral blood circulation (V max) as differential-diagnostic criterion between leiomyoma and uterine sarcoma. However, at that time, the authors did not find significant differences between the resistance indices (RI) in the leiomyoma $-0.65(0.42-0.90)$ and sarcoma of the uterus $-0.66(0.33-0.77)[10]$.

In the future, in the world, a large number (count goes to thousands) of rather controversial results on the study of hemodynamics of simple, proliferating leiomyomas and sarcomas of the uterus was carried out, using two-dimensional dopplerometry to search for possible differential diagnostic criteria. One part of the authors considers the method to be informative; other researchers do not find reliable ultrasound differences between the blood flow in leiomyomas and uterine sarcomas $[11,12]$. Thus, in a two-dimensional ultrasound with dopplerometry before surgery, a morphologically verified diagnosis of uterine leiomyosarcoma was established in studies in only $13.8 \%$ of cases [13], and according to other studies, the uterine body leiomyosarcoma at the preoperative stage was diagnosed in $68.8-70.8 \%$ of cases of echography $[5,14]$.

Adherents of the of dopplerometry informativity in the differential diagnosis of benign and malignant tumors with the help of the Doppler method believe that the diagnosis is based on various features of the blood supply of these tumors. It is known that the vascularization of benign tumors 
of the myometrium occurs due to the terminal branches of the uterine arteries. The blood flow in them is unidirectional, with low speed and constant diastolic component $[15,16]$. Blood supply of malignant tumors occurs due to newly formed vessels, mainly capillary type, abnormal in form, chaotically located, having a deficiency of muscle tissue and a large number of arteriovenous anastomoses $[17,18]$. Blood flow in such vessels is characterized by high speed, low vascular resistance and various directions $[19,20]$.

Based on the analysis of the published data of the part of the studies whose authors consider the method of dopplerometry in the two-dimensional mode to be informative for the diagnosis of benign, borderline and malignant myometrium tumors, general differential diagnostic markers were identified: the localization of the detected vessels in the CDM regimen and the rate of vascular blood flow, vascular resistance in the pulsed Doppler mode [1, 12]. For a simple leiomyoma, the absence of a central intra-node localization of blood vessels in the CDM regimen, a low rate of arterial and venous blood flow, as well as an average resistance of arterial blood flow in the regime of impulsive dopplerometry are most typical; in a leiomyoma with eating disorders, the absence of a central intra-node localization of blood vessels, a low rate of arterial and venous blood flow in combination with high arterial resistance were observed more often $[3,6]$. For proliferating leiomyoma, the central intra-node localization of blood vessels and average blood flow velocities with low and medium resistance are characteristic [11, 19]. For sarcoma of the uterus with profuse vascularization, both at the periphery and in the center, high blood flow rates and low resistance are typical. The authors emphasize that there is information about the low specificity of this gradation, since the detection of a central type of vascularization and low resistance values can be in simple myomatous nodes with edema, eating disorders and destruction, and leads to diagnostic errors and suspicion of malignancy [5, 13].

Analysis of numerous publications on the evaluation of blood flow in the uterine arteries by the method of two-dimensional impulse-wave Doppler ultrasound in the ultrasonic differential diagnosis of benign and malignant tumors of the uterus has shown that it has not been finally solved $[21,22]$. Many authors tend to believe that this technique is characterized by high sensitivity, but very low specificity $[23,24]$, since a decrease in the index of uterine artery resistance is observed, both with leiomyoma and with uterine sarcoma [11,12].

Long-term studies of dopplerometric parameters for various morphotypes of uterine leiomyoma (simple, with secondary changes, proliferating) and uterine sarcoma led most researchers to conclude that the following assessment of the velocity characteristics of the blood flow is the following: the rate of arterial blood flow in the node ( $\mathrm{V} \max$ ) is low $<15 \mathrm{~cm} / \mathrm{s}[6,25]$, the average $15-40 \mathrm{~cm} / \mathrm{s}$, high $->40 \mathrm{~cm} / \mathrm{s}[13,26]$. Resistance of arterial blood flow in the node (RI): high $\geq 0.7$, medium $-0.45-0.69$, low $-\leq 0.44$. The velocity of venous blood flow in the node (VVmax): low $-<6 \mathrm{~cm} / \mathrm{s}$, high $-\geq 6 \mathrm{~cm} / \mathrm{s}[5,15]$.

Based on the analysis of dopplerometric indicators of benign and borderline tumors of myometrium, an attempt was made to develop a mathematical model that, in the opinion of the authors, would allow predicting the morphological type of uterine fibroids and a computer program "Probability Proliferation" was developed to simplify the application of the algorithm in practice, but it did not get a wide spread in diagnosis [1].

At the end of the 20th century, 3D-energy dopplerometry was used to objectify data on the hemodynamics of myometrium tumors with a quantitative assessment of the volume and intensity of the vascular channel flow with calculations of volumetric vascularization indices using the Virtual Organ Computer-aided Analysis (VOCAL) option, which allows quantifying the degree of severity perfusion of the tumor $[17,27]$. To this end, some 3D indicators were proposed reflecting perfusion - the Vascular Index (VI), the Flow Index (FI), the Vascular Flow Index (VFI). The higher the value of these indicators, the greater the perfusion of the tumor [3, 28].

We analyzed data on the informativity of the 3D-energy Doppler ultrasound in the diagnosis of uterine tumors $[29,30]$. The analysis showed that the patterns of changes in VI and VFI and FI in patients with uterine leiomyoma related to cycle phases and age, as well as in healthy women, in general, persisted $[27,31]$. The assumption that the settings of the ultrasound scanner and the 
cardiac cycle of women can influence the parameters of 3D energy dopplerometry in evaluating the vascularization of uterine leiomyoma have not been confirmed in the studies [32].

According to the published data, the indices of the three-dimensional blood flow indexes reflecting the hemodynamics of the uterus affected by the leiomyoma decreased as the volume of the uterus increased in such patients. Thus, when the uterus volume was $150 \mathrm{~cm}^{3}$, VI was more than 4 times less than with a uterus volume of $75 \mathrm{~cm}^{3}(2.3 \%$ and $9.7 \%$, respectively), and VFI was more than three times lower ( 0.9 and 3.3 , respectively). The authors concluded that such a dynamics of indicators of volumetric blood flow indices reflects a decrease in the vascularization of the uterus affected by the leiomyoma. The indices of the FI flux index in the studies were rather monotonous and did not have significant differences in the groups of women of different ages and in different volumes of the uterus lesion affected by the leiomyoma [2, 33].

After studying the perfusion of tumors in myometrium, the first very interesting results were obtained using 3D-energy Doppler. Thus, it was found that in comparison with healthy myometrium (VI - $4.4 \%$, VFI - 1.6) in a simple leiomyoma of the uterus with ischemia and edema 3D perfusion indices were significantly less $(\mathrm{VI}-0.9 \%$, VFI -0.3$)$, while in the proliferating uterine leiomyoma - significantly more (VI - $6.6 \%$, VFI - 2.8) [34].

This allowed researchers to look for more reliable differential diagnostic criteria for benign and malignant tumors of myometrium with the help of 3D echography, in comparison with the two-dimensional echography, in connection with which the study of volumetric indices of vascularization with the use of the VOCAL option of 73 patients with myometrium tumors in the subsequent surgical treatment was performed. In retrospect, the authors compared the information content of these two- and three-dimensional ultrasound studies. Including indicators of volumetric indices of vascularization - VI, FI, VFI, and were compared with the results of the histological structure of the removed tumors (simple leiomyoma, proliferating leiomyoma, sarcoma of the uterus). The study of uterine perfusion by the method of 3D energy Doppler ultrasound allowed the authors to conclude that the threshold value of VI proliferating uterine and sarcoma leiomyoma should be considered $7.0 \%$. When comparing the degree of vascularization of the node and the uterus as a whole, the following regularity was revealed: a simple myoma always had VI, FI, VFI is less than the uterus as a whole, while in the cases of proliferative leiomyoma and sarcoma of the uterus the value of these indices proved to be significantly higher than the uterus as a whole. The authors concluded that to take a decision on the method of treatment of patients with uterine leiomyoma, the data of 3D energy dopplerography with a quantitative evaluation of the volume and intensity of the blood flow of the uterine vascular bed and nodes with calculations of volumetric indices of vascularization using the VOCAL option should be taken into account, which, in their opinion, turned out to be especially significant $[2,3]$.

\section{Results}

Based on the review of the literature data on the importance of the study of hemodynamics of uterine tumors by the method of dopplerometry in the two-dimensional mode of echography for differential diagnosis of simple proliferating leiomyomas and sarcomas of the uterus, the specificity of known ultrasonic and dopplerometric indicators in the detection of oncopathology is clear [35, 36].

Three-dimensional echography, according to the literature, has become a new stage in the development of ultrasound diagnostics in the detection of uterine pathology $[37,38]$. The study of perfusion of myometrium tumors using the 3D-energy dopplerometry method allows us to hope for a search for more reliable method, in comparison with the two-dimensional regime, and malignant tumors of myometrium. However, many questions of this problem remain unexplored, and the obtained data are contradictory. The number of published works is not numerous and is presented in a small number of observations. A single diagnostic algorithm for detecting this pathology using the methods of three-dimensional ultrasound is absent.

\section{Conclusions}

1. Analysis of the literature data showed that the place of three-dimensional ultrasound in the diagnosis of myometrium tumors is not definitively determined. In this connection, it is actual 
to search for new three-dimensional ultrasound and dopplerometry diagnostic differential diagnostic criteria that allow excluding or minimizing the subjective component of the study, which is characteristic of a two-dimensional echography.

2. Development and introduction of a new method for diagnosing simple, proliferating leioe myomas and sarcomas of the uterus using various techniques of three-dimensional echography with the development of quantitative parameters of 3D energy dopplerometry will significantly increase the level of ultrasonic diagnostics in oncogynecology.

\section{References}

[1] Babkina, A. V., Krutova, V. A., Naumova, N. V. (2014). Vozmognosti echografii v differencialnoy diagnostike prostoy i proliferiruyushey myomy matki subserosnoy lokalizacii [Possibilities of echography in differential diagnosis of simple and proliferating uterine fibroids of subserous localization]. Basic research, 2, 23.

[2] Devitskiy, A. A., Ozerskaya, I. A. (2014). Differentsial'naya ul'trazvukovaya diagnostika dobrokachestvennykh i zdokachestvennykh uzlov miometriya [Differential ultrasound diagnosis of benign and malignant myometrium nodes]. Ultrasound and functional diagnostics, 4, 96.

[3] Ozerskaya, I. A., Devitskiy, A. A. (2014). Ul’trazvukovaya differentsial'naya diagnostika uzlov miometriya $\mathrm{v}$ zavisimosti ot gistologicheskogo stroyeniya opukholi [Ultrasound differential diagnosis of myometrium nodes depending on the histological structure of the tumor]. Medical imaging, 2, 110-121.

[4] Gu, Y., Zhu, L., Liu, A., Ma, J., Lang, J. (2014). Analysis of hysterectomies for patients with uterine leiomyomas in China in 2010. International Journal of Gynecology \& Obstetrics, 129 (1), 71-74. doi: http://doi.org/10.1016/j.ijgo.2014.10.031

[5] Abdullayev, R. Ya., Sukhin, V. S., Semikoz, N. G., Sukhina, E. N., Pozdnyakov, S. A. (2013). Vozmozhnosti ul'trasonografii v diagnostike sarkomy matki [The possibilities of ultrasonography in the diagnosis of uterine sarcoma]. Women's health, 6, 161-164.

[6] Zaporozhchenko, M. B. (2015).Sostoyaniye regional'noy gemodinamiki v sosudakh matki u zhenshchin reproduktivnogo vozrasta s leyomiomoy matkiThe state of regional hemodynamics in uterine vessels in women of reproductive age with uterine leiomyoma]. Arta Medica, 1 (54), 41-44.

[7] Abdullayev, R. Ya., Pozdnyakov, S. A., Mikhanovs'kyi, A. A. (2010). Rol' dopplerometriyi hilok matkovykh ven $\mathrm{v}$ dyferentsial'niy diahnostytsi pukhlyn tila matky ta endometriya [The role of dopplerometry of the branches of uterine veins in the differential diagnosis of tumors of the uterus and endometrium]. International Journal of Medicine, 1, 96-99.

[8] Kurjak, A., Zalud, I., Jurkovic, D., Alfirevic, Z., Miljan, M. (1989). Transvaginal Color Doppler for the Assessment of Pelvic Circulation. Acta Obstetricia et Gynecologica Scandinavica, 68 (2), 131-135. doi: http://doi.org/10.3109/00016348909009900

[9] Bourne, T., Campbell, S., Steer, C., Whitehead, M. I., Collins, W. P. (1989). Transvaginal colour flow imaging: a possible new screening technique for ovarian cancer. BMJ, 299 (6712), 1367-1370. doi: http:// doi.org/10.1136/bmj.299.6712.1367

[10] Hata, K., Hata, T., Maruyama, R., Hirai, M. (1997). Uterine sarcoma: can it be differentiated from uterine leiomyoma with Doppler ultrasonography? A preliminary report. Ultrasound in Obstetrics and Gynecology, 9 (2), 101-104. doi: http://doi.org/10.1046/j.1469-0705.1997.09020101.x

[11] Markhabullina, D. Sh., Khasanov, A. A. (2015). Dopplerometriya sosudov matki - metod otsenki proliferativnoy aktivnosti miomatoznykh uzlov [Dopplerometry of the uterine vessels - a method for evaluating the proliferative activity of myoma nodes]. Ulyanovsk Medical Biological Journal, 3, 8-13.

[12] Idowu, B. M., Ibitoye, B. O. (2018). Doppler sonography of perifibroid and intrafibroid arteries of uterine leiomyomas. Obstetrics \& Gynecology Science, 61 (3), 395-403. doi: http://doi.org/10.5468/ ogs.2018.61.3.395 
[13] Simonchuk, Ye. V., Sharma, N. A. (2016). Leyomiosarkoma matki - printsipy diagnostiki i lecheniya [Leiomyosarcoma of the uterus - principles of diagnosis and treatment]. Women's health, 5 (111), 156-159.

[14] Mnatsakanyan, I. K., Chekalova, M. A., Lazareva, N. I., Fedenko, A. A. (2014). Ul’trazvukovaya diagnostika metastazov leyomiosarkomy matki [Ultrasonic diagnosis of metastases of uterine leiomyosarcoma]. Sarkomas of bones, soft tissues and skin tumors, 3-4, 37-44.

[15] Mioma matki: diagnostika, lecheniye, reabilitatsiya. Klinicheskiye rekomendatsii po vedeniyu bol'nykh [Uterine fibroids: diagnosis, treatment, rehabilitation.Clinical recommendations for managing patients] (2015). Moscow: GBOU VPO «The First Moscow State Medical University», 101.

[16] Samani, F. G., Jabbary, R., Mashrabi, O. (2012). Study of uterine artery blood flow in leiomyomatous uterus. Life Sciences Journal, 9, 583-586.

[17] Bulanov, M. N. (2012). Ul’trazvukovaya ginekologiya [Ultrasonic gynecology]. Moscow: Publishing House Vidar, 456.

[18] Rauh-Hain, J. A., del Carmen, M. G. (2013). Endometrial Stromal Sarcoma. Obstetrics \& Gynecology, 122 (3), 676-683. doi: http://doi.org/10.1097/aog.0b013e3182a189ac

[19] Babkina, A. V., Krutova, V. A., Naumova, N. V. (2014). Vozmozhnosti ekhografii v differentsial'noy diagnostike prostoy i proliferiruyushchey korporal'noy miomy matki [Possibilities of echography in differential diagnosis of simple and proliferating corporal uterine myoma]. Kuban scientific medical bulletin, 4, 15-20.

[20] Gyanchandani, M., Adiga, C. P., Goolahally, L. N., Itagi, R. M., Kalenahalli, K. V. (2016). Endometrial stromal sarcoma: An aggressive uterine malignancy. Journal of Radiology Case Reports, 10 (9), 35-43. doi: http://doi.org/10.3941/jrcr.v10i9.2770

[21] Idowu, B., Ibitoye, B., Adetiloye, V. (2017). Uterine Artery Doppler Velocimetry of Uterine Leiomyomas in Nigerian Women. Revista Brasileira de Ginecologia e Obstetrícia / RBGO Gynecology and Obstetrics, 39 (9), 464-470. doi: http://doi.org/10.1055/s-0037-1604489

[22] Dolenko, O. V. (2016). Differentsial'nyye kriterii ekhografii i lecheniya uzlovoy leyomiomy matki u zhenshchin reproduktivnogo vozrasta [Differential criteria for echography and treatment of nodal uterine leiomyoma in women of reproductive age]. International Medical Journal, 4, 38-41.

[23] Chekalova, M. A., Mnatsaakanyan, L. K., Kuznetsov, V. V., Zakharova, T. I., Dvorova, Ye. K. (2009). Vozmozhnosti ekhografii pri diagnostike leyomiosarkomy tela matki [Opportunities of echography in the diagnosis of leiomyosarcoma of the body of the uterus]. Siberian Cancer Journal, 3 (33), 10-14.

[24] Dombrovs'kiy, V. I., Berlim, Yu. D., Cherkasov, M. F., Cherkasov, D. M., Matsionis, A. Ye., Mineyev, N. I., Voloshin, V. V. (2015). Luchevaya diagnostika gigantskoy miomy matki [Diagnostic imaging of a giant myoma of the uterus]. Russian Electronic journal of radiology, 5 (3), 74-89. Available at: http://rejr. $\mathrm{ru} /$ volume/19/9.pdf

[25] Bulun, S. E. (2013). Uterine Fibroids. New England Journal of Medicine, 369 (14), 1344-1355. doi: http://doi.org/10.1056/nejmra1209993

[26] Simonchuk, E. V., Boyko, A. B. (2015). Sarkomy matki (zabolevayemost', klinika, diagnostika) [Sarcoma of the uterus (incidence, clinic, diagnosis)]. Women's health, 6 (102), 189-191.

[27] Ozerskaya, I. A. (2013). Ekhografiya v ginekologii [Echography in gynecology]. Moscow: Publishing House Vidar, 564.

[28] Anisimov, A. V. (2010). VOCAL - kolichestvennyy analiz v trekhmernoy ekhografii [VOCAL quantitative analysis in three-dimensional echography]. SonoAce Ultrasound, 21, 89-95.

[29] Andreotti, R. F., Fleischer, A. C. (2014). Practical Applications of 3D Sonography in Gynecologic Imaging. Radiologic Clinics of North America, 52 (6), 1201-1213. doi: http://doi.org/10.1016/j.rcl.2014.07.001

[30] Rashid, S. Q., Chou, Y.-H., Tiu, C.-M. (2016). Ultrasonography of Uterine Leiomyomas. Journal of Medical Ultrasound, 24 (1), 3-12. doi: http://doi.org/10.1016/j.jmu.2015.12.006 
[31] Tukhbatullin, M. G., Aliyeva, I. M. (2012). Sovremennyye ul'trazvukovyye tekhnologii v klinicheskoy praktike [Modern ultrasonic technologies in clinical practice]. Practical medicine, 5 (12). Available at: http://pmarchive.ru/sovremennye-ultrazvukovye-texnologii-v-klinicheskoj-praktike

[32] Nieuwenhuis, L. L., Hehenkamp, W. J. K., Brolmann, H. A. M., Huirne, J. A. F. (2017). 3D power Doppler in uterine fibroids; influence of gain, cardiac cycle and off-line measurement techniques. Journal of Obstetrics and Gynaecology, 38 (1), 103-109. doi: http://doi.org/10.1080/01443615.2017.1330323

[33] Juan Luis Alcazar, J. (2013). Three-dimensional Static Ultrasound and 3D Power Doppler in Gynecologic Pelvic Tumors. Donald School Journal of Ultrasound in Obstetrics \& Gynecology, 7 (2), 187-199. doi: http://doi.org/10.5005/jp-journals-10009-1283

[34] Buyanova, S. N., Titchenko, L. I., Titchenko, I. P. (2007).Vozmozhnosti sovremennykh UZ tekhnologiy v opredelenii kliniko-patogeneticheskogo varianta miomy [Possibilities of modern ultrasound in determining the clinical and pathogenetic variant of myoma]. The Russian bulletin of the obstetrician-gynecologist, 5, 36-38.

[35] Chekalova, M. A., Mnatsakanyan, I. K., Mnatsakanyan, L. K. (2016). Vozmozhnosti ekhografii $\mathrm{v}$ diagnostike endometrial'noy sarkomy matki [The possibility of ultrasound in the diagnosis of endometrial uterine sarcoma]. Ultrasonic and functional diagnostics, 6, 40-51.

[36] Volik, N. K. (2012). Sovremennyye metody luchevoy diagnostiki onkologicheskikh zabolevaniy $\mathrm{u}$ zhenshchin [Modern methods of radiation diagnosis of cancer in women]. Health of Ukraine, 2 (17), 3-5. Available at: http://health-ua.com/pics/pdf/ZU_2012_Onko_4/03-05.pdf

[37] Kaminskiy, V. V., Dunayevskaya, V. V. (2012). Sravnitel'naya kharakteristika trekhmernoy ekhografii i sonoyelastografii pri differentsial'noy diagnostike miomy matki [Comparative characteristics of three-dimensional echography and sonolastography in differential diagnosis of uterine fibroids]. Pediatrics, obstetrics and gynecology, 6, 76-79.

[38] Lagana, A. S., Ciancimino, L., Mancuso, A., Chiofalo, B., Rizzo, P., Triolo, O. (2014). 3D sonohysterography vs hysteroscopy: a cross-sectional study for the evaluation of endouterine diseases. Archives of Gynecology and Obstetrics, 290 (6), 1173-1178. doi: http://doi.org/10.1007/s00404-014-3366-6 